\title{
The Influence of the Development of Digital Economy on the Upgrading of China's Industrial Structure
}

\author{
Yaling $\mathrm{LI}^{1}$ \\ ${ }^{1}$ School of Business and Tourism Management, Yunnan University, Chenggong District, Kunming City, Yunnan Province, China, 650500
}

\begin{abstract}
Nowadays, with the rapid development of the Internet, all walks of life are closely connected with the development of the Internet. Differences in the degree of integration between different industries and the Internet make the leading industries of the national economy constantly change, thus promoting the transformation and upgrading of the industrial structure. The impact of Internet development on the upgrading of industrial structure is not only that the interconnected technologies and platforms change the traditional economic model, but also that the integration of Internet and industry has a profound impact on the industrial structure.
\end{abstract}

\section{INTRODUCTION}

The upgrading of industrial structure includes two levels: the upgrading of three industries and the upgrading within the manufacturing industry.

From the perspective of the three major industries, industrial structure upgrading usually refers to the transformation and adjustment of industrial structure from the low-level state to the high-level state. The advanced state of industrial structure usually means that in different industrial sectors of a country (region), the industry with high productivity becomes the leading industry of national economy. Countries all over the world have experienced the law that the proportion of primary industry continues to decline, the proportion of secondary industry first rises and then falls, and the proportion of tertiary industry continues to rise. China's industrial structure upgrading is basically in line with this big law.

The second level of industrial structure upgrading is the internal structure upgrading of the manufacturing industry. From the experience of various countries, there are generally from labor-intensive industries (such as textile and clothing industry) to capital-intensive industries (such as heavy and chemical industry), and then to technology-intensive industries (such as electronics, biological industries) transformation and upgrading.

Nowadays, with the rapid development of the Internet, all walks of life are closely connected with the development of the Internet. Differences in the degree of integration between different industries and the Internet make the leading industries of the national economy constantly change, thus promoting the transformation and upgrading of the industrial structure.

\section{THE THEORETICAL BASIS OF INDUSTRIAL TRANSFORMATION AND UPGRADING}

\subsection{Theory of industrialization}

The theory of industrialization points out that each country has different leading industries in different stages of industrialization. In the early stage of industrialization, the leading industries in the economy were light industries such as food, textile and clothing. In the middle stage of industrialization, the leading industries of the economy were petroleum, chemical industry, machinery, electronics, electric power, energy and raw material industry, namely, heavy and chemical industry. By the late stage of industrialization, the leading industries in the economy were automobile, equipment, electronic information and other high-tech, high-value-added manufacturing. In the post-industrialization period, the leading industry of the economy is the service industry.

The reasons for the upgrading of industrial structure include two aspects: first, due to the different levels of technological progress of different industrial sectors, and the huge differences in technological absorption capacity and technical requirements, the growth rates of various industries are different to some extent, which leads to the changes in the industrial structure of a country (region). The second is the development of a country (region) in different stages by different dominant industry of national economy is needed to promote the development of the country (region), along with the leading industry of the national economy changes directly affect the country (region) of production and consumption, this essentially makes a country (region) great changes in the industrial structure. Therefore, industrial structure upgrading is a 
process of successive replacement of regional leading economic sectors and absorption of technological progress.

\subsection{International trade theory}

International trade theory points out that each country should mainly produce the industries with its most comparative advantage in different stages. When a country reaches the later stage of industrialization, or the postindustrial era, it should mainly concentrate on producing high-tech and high-value-added industries, while transferring labor-intensive and low-value-added industries to other countries.

Combining these two theories, it can be concluded that the upgrading of industrial structure is a universal law.

\section{DIGITAL DEVELOPMENT HAS PROVIDED IMPORTANT OPPORTUNITIES FOR THE TRANSFORMATION AND UPGRADING OF CHINA'S TRADITIONAL MANUFACTURING INDUSTRY}

China has a large population and a large labor base. If effective measures cannot be taken to support low-skilled labor-intensive industries, these industries will lose competitiveness quickly or even transfer to other countries in large Numbers, which may cause serious employment problems.

In this way, countries with relatively small economies in history can take the road of industrial structure upgrading, transfer a large number of traditional industries abroad, and then focus on advanced industries, but It is difficult for China to replicate the same path. China's industrial upgrading must pay special attention to the transformation and upgrading of traditional manufacturing industry, which should shift from structural upgrading to quality improvement, quality and technological innovation. This is not only a unique challenge for China's industrial upgrading, but also an opportunity for China's industrial upgrading.

The most striking feature of the new round of scientific and technological revolution and industrial revolution is the digital, intelligent, platform-based and serviceoriented development of the manufacturing industry. Among them, the development of digitalization and intelligence provides the possibility to solve the problem of rising labor cost and labor shortage commonly faced by other countries at this stage. With the development of information technology, digitalization runs through the whole process of product demand, research and development, design, production, marketing and service, providing an important foundation for optimizing product life cycle management and supporting intelligent production.

And industrial 4.0, the development of intelligent manufacturing technology, especially the intelligent robot of large-scale application, low cost, make many laborintensive industries to capital-intensive industries, manufacturing system have certain autonomy of perception, learning, analysis, decision-making and communication and coordination ability, so that it can realize high quality, efficient, flexible, low consumption, clean production, also can solve the problem of rising labor costs and labor shortages.

With the rise of industrial Internet, the development trend of platformization and servitization of manufacturing industry is increasingly prominent. The cost of informatization, digitization and intelligentization of traditional industries has been greatly reduced and the space for value appreciation has been greatly enhanced. The industrial Internet platform is characterized by sharing, connection of things, interconnection and intelligence. It can help smes reduce informatization costs, tap production potential, improve operational efficiency, carry out upstream and downstream collaboration and improve intelligent manufacturing capabilities. It is an important late-mover advantage for China. Through innovation and optimization of production organization, operation and management mode and business development mode, manufacturing enterprises continue to increase the proportion of service factors in input and output, and constantly extend and upgrade the value chain. Traditional industries also have a broad space for improvement.

\section{THE DIRECTION OF CHINA'S INDUSTRIAL UPGRADING: DIGITAL TRANSFORMATION}

In the context of a new round of scientific and technological revolution and industrial transformation, digital transformation will be an important direction or goal of China's industrial upgrading. Digital transformation itself will be a process of first making things easier and then making things harder. So far, China's digital transformation has formed new models and new forms of business, mainly in the field of consumption or services. During the coVID-19 outbreak in 2020, digitalization played an important supporting role in epidemic prevention and control and resumption of work and production. After the epidemic, the focus of China's digital transformation will inevitably shift from consumption or service to manufacturing.

"The new round of scientific and technological revolution and industrial revolution" is also called "the fourth Industrial Revolution". From the perspective of innovation economics, it can also be regarded as "the sixth technological revolution". The industrial revolution began around 2010; The full commercial application of $3 \mathrm{G}$, big data, cloud computing and other technologies should be in 2009. Take $3 \mathrm{G}$ apps. China's first $3 \mathrm{G}$ license was issued in January 2009. It can be said that the large-scale commercial application of the new generation of information technology, represented by the Internet of Things, $3 \mathrm{G} / 4 \mathrm{G} / 5 \mathrm{G}$, big data analysis and so on, has opened the prelude of the industrial revolution.

In terms of application results, in the past decade, platform economy, sharing economy, or online and offline local services, online crowdsourcing, Internet finance... New models and forms of business are emerging. Or some 
of the existing economic model in the form of digital implementation have been updated, such as economy, sharing platform, in the era of industrial economy and agricultural economy will exist this kind of economic form, and in the digital economy era, the emergence of network platform and business process of digital upgrade makes these economic form coruscate gives infinite vitality and vigor.

So far, it can be said that China's digital transformation or the formation of new models and new forms of business, mainly in the field of consumption or services. Behind the driver probably mainly in the comprehensive commercial application of a new generation of information technology, make the data elements, from the production cost, to $3 \mathrm{~g}$, $4 \mathrm{~g}, 5 \mathrm{~g}$ after application of transmission cost, storage cost of cloud storage, the processing cost of cloud computing, including the now large data analysis technology and deep learning iteration and optimization technology, makes the data generation, transmission, processing, analysis and so on various aspects of the cost has dropped sharply, basically achieved zero marginal cost. In this context, data is the new key.

Why are there so many new models and forms of business emerging in the consumption or service sector? The original scenario may be the economic activity in the field of consumption, service or transaction involving data information collection, processing and analysis, which is relatively simple. Moreover, its mode is more universal and does not require too much transformation, so it has a wider range of audiences and grows more rapidly.

Accelerate the development of industrial Internet and promote the realization of intelligent manufacturing. The digitization and intellectualization of the manufacturing industry put forward higher requirements for the performance of the new generation of information technology-related technologies.

\section{CHINA'S ADVANTAGES AND CHALLENGES IN PROMOTING DIGITAL TRANSFORMATION}

The advantages of the digital transformation of China's manufacturing industry are as follows. The first is the construction of new types of infrastructure. The government work report also emphasized strengthening the construction of new infrastructure, developing a new generation of information network and expanding $5 \mathrm{G}$ application. New infrastructure such as $5 \mathrm{G}$, industrial Internet and artificial intelligence can be said to be the basis for large-scale application of the new generation of information technology. In the future, intelligent factories, driverless vehicles, telemedicine (surgery) and many other application scenarios will require a data transmission network with low delay, large capacity and high speed. At present, the Chinese government is leading the development of new infrastructure, which not only conforms to the trend of scientific and technological revolution in the world, but also provides strong support for China to deepen digital transformation and promote industrial consumption upgrading.

Secondly, from the perspective of data elements, according to the theory of comparative advantage, the huge advantage of Chinese netizens in social and consumption scenarios has been transformed into the endowment advantage of data elements. China's central government has also issued two documents related to activities regulating data elements. With the promotion of the government, China's data factor market is expected to be further standardized in the future, so that the endowment advantages of data factors can provide a stronger guarantee for the promotion of digital transformation and the realization of the sustained medium-high growth of the macro economy.

Of course, China's digital transformation is also facing some bottlenecks and obstacles, such as integrated circuits and high-end chips. To break through these technological bottlenecks and weak links, we need to strengthen investment in scientific research and tackle key problems. At the same time, we need to strengthen the application of self-developed technologies in cooperation with institutional reform. Through the application of accelerated technology optimization iteration, gradually break through the bottleneck.

\section{CONCLUSION}

At present, with the rapid development of new technologies such as digital economy, platform economy, sharing economy and intelligent interconnection, a new round of scientific and technological revolution and industrial transformation is emerging. This new industrial revolution, characterized by intelligent interconnectivity between people, machines and resources, is increasingly blurring the boundaries between the physical and digital worlds, industries and services, providing unlimited opportunities for more efficient and environmentally friendly economic growth.

There is no doubt that the new round of industrial revolution will have a more profound impact on the global industry and provide an important window of opportunity for China's industrial upgrading. As the world's second largest economy, China has a huge economic size and market scale. It has certain advantages in emerging fields such as the digital economy and has the economic and industrial foundation to deeply participate in the new industrial revolution.

At the same time, however, China's industrial transformation and upgrading are also facing many challenges at home and abroad. Anti-globalization and rising trade protectionism have also brought great uncertainties to industrial transformation and upgrading and enterprise development.

\section{References}

1. Czernich N.O. Falck, T. Kretschmer et al. Broadband Infrastructure and Economic Grow th[J], Social Science Electronic Publishing. 2011, 121:505-532.

2. Koutroumpis, $P$, The Economic Impact of Broadband on Growth: A Simultaneous Appro ach[J], Telecommuni-cations Policy. 2009, 33:471-485. 
3. Alvarez-Cuadrado, F. and M. Poschke, Structural Change out of Agriculture: Labor Pu sh versus Labor Pull[J], American Economic Journal: Macroeconomics. 2011, 3(3):27-58.

4. Peneder, M. Industrial Structure and Aggregate Growth[J]. Structural Change and Econo mic Dynamics. 2002, 14:427-448.

5. Dettling, L.J. Broadband in the Labor Market: The Impact of Residential High Speed Internet on Married Women's Labor Force Participation[J]. Industrial Labor Relations Revie w, 2017, 70(3):451-482

6. Kuhn, P and H. Mansour. Is Internet Job Search Still Ineffective? [J]. Economic Journ al, 2014, 124(581):1213-1233

7. Duna Ruijing. Technological Progress, Technological Efficiency and Industrial Structure Upgrading -Based on the Spatial Measurement test of 285 Cities in China [J]. Research and Development Management, 2018, 30(06):106-116.

8. Li Dongkun, Den Ming. China's Inter-provincial OFDI, Spatial Spillover and Industrial Structure Upgrading -- An Empirical Analysis Based on the Durbin Model of Spatial Panel [J]. Journal of International trade, 2016, (01):121-133.

9. Lv Mingyuan, Cheng Lei. Empirical Analysis of the Impact of "Internet + " on the Ecological Transformation of Industrial Structure -- Based on the Data of Shanghai from 2000 to 2013 [J]. Shanghai Economic Review, 2016, (09):110-121.

10. Tang Demiao. The New Industrial Revolution and the Integration of the Internet Industry Reform [J]. Study on Financial Issues, 2015, (08):24-29.

11. Xu Leicheng, Fan Aijun. The Path of Optimization and Upgrading of Manufacturing Structure Driven by Internet Technology -- Empirical Evidence from China's Inter-provincial Panel Data [J]. Journal of Shanxi University of Finance and Economics, 2018, 40(07):45-57.

12. Gan Chunhui, Wang Qinag. The Change of China's Industrial Structure Since the Reform and Opening Up: Review and Prospect [J]. Economics and Management Research, 2018, 3 9(08):3-14. 